\title{
Исследование закономерностей развития корпоративной социальной ответственности в России на основе специализированного рейтинга
}

\section{Иделя Бадыкова}

Казанский национальный исследовательский технологический университет, г. Казань, Россия

Информация о статье

Поступила в редакциюю:

13.08.2020

Принята

к опубликованию:

28.11.2020

УДК 338.49

JEL H54, R40

Ключевые слова: корпоративная социальная ответственность, раскрытие информации, рейтинг, российские компании

\section{Keywords:}

corporate social responsibility, information disclosure, rating, Russian companies

\begin{abstract}
Аннотация
Целью данного исследования выступает изучение тенденций, связанных с уровнем социальной ответственности российских компаний. Для решения поставленных задач использована авторская методика составления рейтинга раскрытия информации о корпоративной сочиальной ответственности. Полученные результаты свидетельствуют о том, что в иелом компании из выборочной совокупности раскрывают около 75\% рассматриваемых критериев. При этом лидеры рейтинга представлены большей частью секторами добычи и переработки нефти и газа, химической промышленности и электроэнергетики, что может свидетельствовать об их стремлении отчасти компенсировать наносимый обществу и экологии вред.
\end{abstract}

Investigation of Corporate Social Responsibility Development Patterns in Russia Based on the Specialized Rating

Idelia Badykova

\section{Abstract}

As part of the research a specialized rating of the corporate social responsibility was compiled based on the author's methodology. Data was collected for the sample of 106 Russian public companies in the non-financial sector. On average, the disclosure rate of all indicators is as high as $75 \%$. The most responsible companies, disclosing information on 25 to 27 out of 27 criteria, were identified to form the list of 29 companies. Most of them appear to belong to oil and gas sector, chemical and energy industries.

One of the possible explanations for that trend is that these areas tend to attract negative attention of the society. Accordingly, it can be assumed that the companies from the mentioned sectors act reasonably to compensate for their negative impact on the environment and society.

It should also be noted that the companies represented by these sectors are usually large and have sufficient resources. 
According to the inadequate resources theory, companies participate in socially responsible projects when they have the resources to do so. However, this theory is relevant for the emerging markets, while stakeholder and signaling theories are more equitable for leading economies.

The companies included into the sample show the highest level of the environmental impact disclosure, which may be explained by the fact that most of the companies are industrial with significant negative impact on the environment.

In general, this study is a subject to a number of disadvantages. Firstly, the sample was quite small. Accordingly, the conclusions presented may be somewhat skewed and limited. Secondly, econometric models should be used. to present more reasonable results. That is planned to be the next stage of the research. Nevertheless, in our opinion, in general, the results obtained reflect the main trends in the development of the corporate social responsibility in Russia.

\section{Введение}

События, развернувшиеся по всему миру в 2019-2020 гг., включая глобальный экономический кризис и пандемию COVID-19, представили собой серьезные препятствия на пути благополучного существования бизнеса. Компании по всему миру начали искать резервы для выживания. В России, например, большинство компаний начали стремиться к получению поддержки со стороны государства. Опыт же развитых стран показал, что в наиболее выигрышном свете оказались социально ответственные компании с длительным опытом работы по данному направлению (например, Google, Lego, Bosch и т.д.). Прежде всего, важную роль сыграло лояльное отношение со стороны значительного количества групп стейкхолдеров, включая потребителей, сотрудников, собственников капитала и т.д.

В России корпоративная социальная ответственность (далее - КСО) в современном ее понимании представляет собой достаточно молодое направление работы компаний: только в начале 2000-ых гг. начал использоваться соответствующий термин и осуществляться действия, ассоциирующиеся с социальной ответственностью, в то время как повсеместное распространение КСО в развитых зарубежных странах имело место уже в 1960-70-е гг.

Особый интерес представляет раскрытие КСО, так как именно оно является важным условием для того, чтобы сформировалось лояльное отношение со стороны стейкхолдеров. В рамках данного исследования будет рассмотрен отечественный опыт раскрытия информации о социальной ответственности компании.

Таким образом, целью данного исследования является изучение тенденций, связанных с уровнем социальной ответственности российских компаний.

\section{Обзор литературы о раскрытии КСО в мире и в России}

Уровень раскрытия информации о КСО, согласно ряду ученых, является частью самой социальной ответственности [1]. Кроме того, с целью достижения инструментальных последствий КСО в долгосрочной перспективе, а именно повышения финансовой эффективности компании, можно сделать допущение о том, что если предприятие осуществляет какие-либо социально ответственные мероприятия и проекты, вероятнее всего, оно будет отображать данную информацию для того, чтобы стейкхолдеры (к примеру, собственники капитала, потребители, сотрудники, местные сообщества, государ- 
ство и т.д.) узнали о данном направлении его деятельности и стали более лояльны по отношению к ней.

Имеется ряд эмпирических исследований [2-4], показывающих какие компании в большей степени склонны к социальной ответственности и ее раскрытию. К таким факторам относят размер компании (чем больше, тем выше уровень КСО) [2], отраслевую специфику (чем больше внимания привлекает сектор, тем выше) [3], финансовую результативность (прямая зависимость) [4], уровень рисков (прямая зависимость) [2] и т.д. Таким образом, можно утверждать, что на раскрытие информации о КСО оказывает влияние множество факторов.

Среди российских ученых также есть те, кто исследуют проблемы информационной открытости в области КСО. В качестве основных примеров можно привести работы Б.С. Батаевой [5], И.Ю. Беляевой [6], М.А. Измайловой [7], Н.Р. Кельчевской [8] и других авторов. К примеру, М.А. Измайлова [7] предлагают систему оценки качества раскрытия информации по четырем уровням. Н.Р. Кельчевская с соавт. [8] же оценивают при помощи интегрального показателя уровень раскрытия информации с целью осуществления эмпирического анализа влияния раскрытия информации на стоимость акционерного капитала.

\section{Рейтинги как фактор стимулирования компаний в росту КСО}

Раскрытие компаниями данных о социально ответственной деятельности дает возможность образования рейтингов. Преимуществами подобного ранжирования предприятий выступает то, что заинтересованные лица могут быстро получить информацию о наиболее социально ответственных компаниях, а последние, в свою очередь, стремятся попадать в подобные рейтинги для того, чтобы получить положительную реакцию со стороны стейкхолдеров.

Следует заметить, что на зарубежных рынках встречается большое количество различных рейтингов и индексов.

К основным рейтингам можно отнести:

1. Global CR RepTrak 100. Ежегодный рейтинг AnnualGlobal CR RepTrak анализирует компании по всему миру с хорошей репутацией в вопросе КСО. Особое внимание уделяется рабочей обстановке, управлению и социальной ответственности;

2. CR Magazine (100 Best Corporate Citizens of 2019). Corporate Responsibility Magazine (Журнал о социальной ответственности) выпускает 20-ый ежегодный рейтинг 100 социально ответственных компаний, опираясь на данные об экологических, социальных и управленческих данных и прозрачности компаний в данных вопросах (рассматриваются около 1000 крупнейших компаний в США);

3. Top 100 Corporate Social Responsibility Influence Leaders. Предлагает список 100 лидеров, оказывающих влияние на КСО. Использует их влияние для помощи другим компаниями в вопросах установки и реализации политики КСО;

4. 25 of the World's Most Socially Responsible Companies. Представляет собой список наиболее социально ответственных компаний в мире и тех ме- 
роприятий, которые они инициируют для того, чтобы быть социально ответственными.

В вышеперечисленные мировые рейтинги российские компании на сегодняшний день не входят, однако, к примеру, по данным KPMG, уровень отчетности отечественных компаний вырос до 73\% (69\% в 2015 г.).

К основным индексам КСО относят:

1. Dow Jones Sustainability Index (США). Специализируется на экологической, социальной и управленческой информации об организации;

2. Nasdaq CRD Global Sustainability Index (NQCRD) (CШA). Формируется из данных о компаниях, которые являются лидерами в предоставлении отчетности об устойчивом развитии. Ко вниманию принимаются, в частности, такие показатели как «углеродный след», использование энергии, потребление воды, опасные и безопасные отходы, производственная безопасность, диверсификация рабочей силы, структура менеджмента, инвестиции в социальную сферу;

3. FTSE4Good (Великобритания). Создан для оценки результативности компаний, демонстрирующих высокую степень вовлеченности в экологические, социальные и управленческие мероприятия;

4. HKQAA HSBC CSR Index (Гонконг). Предоставляет информацию о количественном измерении зрелости компании в вопросах социальной ответственности. Разработан на основе стандарта ISO 26000.

В российской практике подобных рейтингов и индексов не так много. Среди основных можно отметить:

1. Рейтинг Ассоциации менеджеров. Ежегодный рейтинг Ассоциации менеджеров «ТОП-50 менеджеров по КСО» определяет социально ответственных менеджеров компаний, осуществляющих деятельность на территории России;

2. Индексы Российского союза промышленников и предпринимателей (далее - РСПП): «Ответственность и открытость» (индекс раскрытия информации) и «Вектор устойчивого развития» (индекс динамики результативности).

Малое количество рейтингов в России, на наш взгляд, порождает две основные проблемы:

1) подобные рейтинги часто выступают дополнительным стимулом для роста КСО, а при их недостаточности и нераспространенности подобного мотивирования не происходит;

2) ученым достаточно сложно проводить эмпирические исследования, в отличие от зарубежных коллег, в связи с тем, что нет стандартизированных данных за продолжительный период времени, по которым можно было бы проводить качественные исследования.

Соответственно, можно говорить о том, что как с практической, так и с научной точек зрения, важно составление рейтингов КСО и предоставление соответствующей информации в открытом доступе.

Автором совместно с А.Б. Анкудиновым ранее была представлена методика составления подобного рейтинга [9]. Он основывается на оценке раскрытия информации по 27 индикаторам: в случае раскрытия проставляется один балл по каждому из критериев, в обратном случае - 0. При этом, индикаторы представлены по трем направлениям: общественные, управленческие, 
экологические. Критерии отобраны в соответствии с международными и российскими стандартами раскрытия информации о КСО, такими как Стандарты отчетности в области устойчивого развития «Глобальной инициативы по отчетности» ${ }^{1}$, AccountAbility AA1000 (Стандарт социальной отчётности компаний AA1000) ${ }^{2}$, Social Accountability International ${ }^{3}$, Руководство по социальной ответственности Международной организации по стандартизации ISO $26000^{4}$, Стандарт «Социальная ответственность организации. Требования» ${ }^{5}$, Социальная хартия российского бизнеса ${ }^{6}$ и т.д.

Общественные индикаторы, в свою очередь, поделены на 3 группы:

1. Ответственность перед персоналом:

- расходы на подготовку, повышение квалификации и обучение персонала;

- социальные расходы на работников, членов их семей и неработающих пенсионеров / социальная поддержка персонала;

- расходы по программе промышленной безопасности;

-оценка рисков, связанных с безопасностью и здоровьем персонала;

-программы и меры, снижающие риски, связанные с безопасностью и здоровьем;

-программы обучения безопасности;

- сотрудничество с профсоюзами;

2. Связь с местными сообществами:

-объем инвестиций в развитие местных сообществ;

-влияние компании на регионы присутствия;

-программы развития местных сообществ;

-программы развития местных поставщиков;

-права коренных малочисленных народов;

3. Взаимодействие с прочими заинтересованными сторонами:

-проявление инициативы в сотрудничестве со стейкхолдерами;

-затраты на благотворительность;

-контроль и/или повышение качества продукции.

Раскрытие информации относительно управленческих аспектов устойчивого развития представлено следующими индикаторами:

- наличие системы управления рисками и системы внутреннего контроля;

- антикоррупционная политика;

-механизмы, исключающие возможность возникновения конфликта интересов;

-наличие этического кодекса организации;

-документальное подтверждение о том, что управление осуществляется согласно одному из международных стандартов.

\footnotetext{
${ }^{1}$ Официальный сайт «Глобальной инициативы по отчетности» (Global Reporting Initiative) [Электронный ресурс]. Режим доступа: https://www.globalreporting.org/.

${ }^{2}$ Официальный сайт AccountAbility [Электронный ресурс]. Режим доступа: https://www.accountability.org/standards/.

${ }_{3}^{3}$ Официальный сайт Social Accountability International [Электронный pecypc]. Режим доступа: http://www.sa-intl.org.

${ }^{4}$ Официальный сайт International Organization for Standardization (Международной организации по стандартизации) [Электронный ресурс]. Режим доступа: https://www.iso.org/ru/home.html.

${ }^{5}$ Социальная ответственность организации. Требования: [Международный стандарт IC CSR-08260008000 (Bсероссийская организация качества)] [Электронный ресурс]. Режим доступа: www.ksovok.com/doc/ic_csr_08260008000_ru.doc.

${ }^{6}$ Социальная хартия российского бизнеса [Электронный ресурс]. Режим доступа: http://rspp.ru/12/6273.pdf.
} 
В качестве критериев по экологическому направлению социальной ответственности представлены следующие:

- наличие экологической политики;

- снижение негативного воздействия на окружающую среду;

- эффективное использование ресурсов, в т.ч. энергетических;

- расходы на охрану окружающей среды;

-мероприятия по охране окружающей среды;

-обращение с отходами;

- экологические характеристики продукции.

На наш взгляд, предложенная методика обладает следующими достоинствами:

1) рассматривается большое количество ключевых показателей, относящихся к КСО;

2) используются данные из официальных источников (отчеты об устойчивом развитии, финансовая отчетность, годовые отчеты и др.), что говорит об их надежности;

3) данная методика помогает определить уровень социальной ответственности любой публичной компании, вне зависимости от того, насколько она социально ответственна.

\section{Статистический анализ КСО российского рынка на основе специализированного авторского рейтинга}

С целью апробирования данной методики составления рейтинга исследована выборка, состоящая из 106 публичных компаний нефинансового сектора. Секторальная принадлежность распределена следующим образом: нефтегазовый $(19,8 \%)$, телекоммуникационный $(9,43 \%)$, металлургический $(11,3 \%)$, транспортный $(6,6 \%)$, строительный $(4,72 \%)$ сектора, сектор добычи полезных ископаемых $(5,7 \%)$, электроэнергетики $(27,36 \%)$, машиностроения $(8,5 \%)$ и пищевой промышленности $(6,6 \%)$.

Компании-лидеры в вопросах социальной ответственности из выборочной совокупности, а именно те предприятия, сумма баллов по раскрытию которых составила 25-27 баллов, представлены в табл. 1. Интересным является определение сферы деятельности подобных компаний. Так, согласно табл. 1, большая часть компаний относится к секторам добычи и переработки нефти и газа, химической промышленности и электроэнергетике.

Данный результат соотносится с эмпирическим исследованием Дж. Хасселдине с соавт. [3], результатом которого стало подтверждение гипотезы о том, что чем больше внимания привлекают сектора, в которых компании осуществляют свою деятельность, тем более они склонны к раскрытию информации о социальной ответственности. Действительно, данные сферы деятельности в рамках российского рынка вызывают непрекращающиеся дискуссии. К примеру, часто принято приводить в пример такие страны как ОАЭ, Норвегию и т.Д., где доход от нефтяной промышленности распределяются между гражданами, в то время как в России он концентрируется в руках отдельных лиц. Безусловно, данное явление воспринимается отрицательно со стороны общества, и требуется определенная компенсация подобного нега- 
тивного воздействия. В результате компании акцентируют внимание на социальной ответственности.

Кроме того, на наш взгляд, также имеет место подтверждение теории о (не)достаточности ресурсов, согласно которой предприятия осуществляют вложения в политику КСО в том случае, если для этого имеются средства. Действительно, компании из данных секторов, как правило, являются крупными и располагают значительными ресурсами.

Таблица 1

ТОП-29 российских компаний по уровню социальной ответственности по итогам 2018 г.

\begin{tabular}{|c|c|c|c|}
\hline $\begin{array}{c}\text { № } \\
\text { пI/II }\end{array}$ & Наименование компании & $\begin{array}{l}\text { Рейтинг } \\
\text { КСО }\end{array}$ & Сфера деятельности \\
\hline 1 & ПАО «НК «РОСНЕФТЬ» & 27 & Добыча и переработка нефти \\
\hline 2 & ПАО «ГАЗПРОМ» & 27 & Добыча и переработка нефти и газа \\
\hline 3 & ПАО «НОВАТЭК» & 27 & Добыча газа, газопереработка \\
\hline 4 & ПАО «Нижнекамскнефтехим» & 27 & Переработка нефти \\
\hline 5 & ПАО Транснефть & 27 & ТЭК \\
\hline 6 & ПАО «МРСК Северо-Запада» & 27 & Электроэнергетика \\
\hline 7 & ПАО «НК «РУССНЕФТЬ» & 26 & Добыча и переработка нефти \\
\hline 8 & ПАО «Лукойл» & 26 & Добыча и переработка нефти и газа \\
\hline 9 & ПАО «АКРОН» & 26 & Химическая промышленность \\
\hline 10 & ПАО «Газпром нефть» & 26 & Добыча и переработка нефти и газа \\
\hline 11 & ПАО «Казаньоргсинтез» & 26 & Химическая промышленность \\
\hline 12 & ПАО «Уралкалий» & 26 & Химическая промышленность \\
\hline 13 & ПАО «ФосАгро» & 26 & Химическая промышленность \\
\hline 15 & ПАО «Русгидро» & 26 & Электроэнергетика \\
\hline 16 & ПАО «ЛенЭнерго» & 26 & Электроэнергетика \\
\hline 17 & ПАО «Кубаньэнерго» & 26 & Электроэнергетика \\
\hline 18 & ПАО «Россети Юг» & 26 & Электроэнергетика \\
\hline 19 & $\begin{array}{l}\text { ПАО «МРСК Центра и Привол- } \\
\text { жья» }\end{array}$ & 26 & Электроэнергетика \\
\hline 20 & ПАО «МРСК Центра» & 26 & Электроэнергетика \\
\hline 21 & ПАО «МРСК Волги» & 26 & Электроэнергетика \\
\hline 22 & ПАО «ФCК ЕЭС» & 26 & Электроэнергетика \\
\hline 23 & АО «Группа «Илим» & 25 & $\begin{array}{l}\text { Целлюлозно-бумажная промыш- } \\
\text { ленность }\end{array}$ \\
\hline 24 & ПАО ГМК «Норильский никель» & 25 & Добыча полезных ископаемых \\
\hline 25 & ПАО «Юнипро» & 25 & Электроэнергетика \\
\hline 26 & ПАО «Якутскэнерго» & 25 & Электроэнергетика \\
\hline 27 & ПАО «Россети Северный Кавказ» & 25 & Электроэнергетика \\
\hline 28 & ПАО «МРСК Сибири» & 25 & Электроэнергетика \\
\hline 29 & ПАО «ТГК 14» & 25 & Электроэнергетика \\
\hline
\end{tabular}

Источник: составлено автором

Кроме того, особенный интерес представляет то, какие направления КСО являются наиболее и наименее раскрываемыми. Как показывает табл. 2, 
в среднем процент раскрытия всех параметров составил 75,09\%. При этом, показатель по экологическим индикаторам является наивысшим $(81,54 \%)$, в то время как для общественных и для управленческих он составляет 73,27\% и $71,70 \%$ соответственно. Однако следует заметить, что общее количество критериев является наибольшим для социального направления (15), так как данная группа включает в себя взаимоотношения с различными группами стейкхолдеров, включая сотрудников компании, местные сообщества и иных.

Таблица 2

Сводная информация о раскрытии рассматриваемыми компаниями КСО

\begin{tabular}{|l|c|c|c|}
\hline $\begin{array}{c}\text { Направление социальной } \\
\text { ответственности }\end{array}$ & $\begin{array}{c}\text { Общее количе- } \\
\text { ство критериев }\end{array}$ & $\begin{array}{c}\text { Среднее количество } \\
\text { баллов по выборке }\end{array}$ & $\begin{array}{c}\text { Процент } \\
\text { раскрытия }\end{array}$ \\
\hline Общественные индикаторы & 15 & 10,99 & 73,27 \\
\hline $\begin{array}{l}\text { Управленческие аспекты } \\
\text { устойчивого развития }\end{array}$ & 5 & 3,58 & 71,70 \\
\hline Экологические индикаторы & 7 & 5,71 & 81,54 \\
\hline Общая оценка & 27 & 20,27 & 75,09 \\
\hline
\end{tabular}

Источник: составлено автором

Вероятнее всего, информация об экологических индикаторах на сегодняшний день является наиболее востребованной как со стороны общества, так и государства. С учетом того, что большая часть выборочной совокупности представлена промышленными предприятиями вопрос воздействия последних на экологию является весьма актуальным.

\section{Заключение}

В рамках данного исследования можно сделать определенные выводы.

На основе авторской методики составления специализированного рейтинга КСО собрана информация о деятельности 106 российских публичных компаний нефинансового сектора. В среднем процент раскрытия всех параметров составил 75\%. Выявлены наиболее социально ответственные компании, которые раскрыли от 25 до 27 критериев из максимальных 27.

Как показал анализ секторальной принадлежности данных предприятий, большая часть компаний относится к секторам добычи и переработки нефти и газа, химической промышленности и электроэнергетике. Данные сферы деятельности, как правило, привлекают внимание со стороны общества, носящее весьма негативный характер. Соответственно, можно предположить, что, проявляя социальную ответственность, они стремятся к компенсации своего негативного воздействия на экологию и общество.

Компании, представленные данными секторами, являются, как правило, крупными и обладают значительными ресурсами. Согласно теории о (не)достаточности ресурсов, социально ответственными выступают те компании, которые располагают свободными средствами для их реализации.

Особое внимание компании из выборочной совокупности уделяют раскрытию информации об экологическом воздействии, что, на наш взгляд, свя- 
зано с тем, что большей частью данные предприятия являются промышленными и оказывают существенное негативное влияние на экологию.

В целом, данное исследование подвержено ряду недостатков.

Во-первых, рассматриваемая выборка является достаточно малой. Соответственно, выводы, представленные в работе, могут носить несколько искаженный и ограниченный характер.

Во-вторых, для получения более обоснованных результатов, в том числе касательно влияния размера, сферы деятельности компании и других параметров предприятия на КСО, представляется логичным использование эконометрических моделей, что представляет собой следующий этап наших исследований. Так, представляется целесообразным составление моделей со случайными эффектами и с фиксированными индивидуальными эффектами. При проведении подобных исследований желательно, чтобы рассматриваемый временной период составлял как минимум 6-8 лет.

Тем не менее, на наш взгляд, в целом полученные результаты должны отражать основные тенденции развития КСО в России.

Таким образом, проведенное исследование, целью которого выступило выявление основных закономерностей развития КСО в рамках российского рынка, является установочным. В рамках дальнейших исследований по данному направлению будет произведен эконометрический анализ полученных данных с целью выявления большего количества закономерностей развития КСО отечественных компаний.

\section{Список источников / References}

1. Beck C., Frost G., Jones S. CSR disclosure and financial performance revisited: A crosscountry analysis. Australian Journal of Management, 2018, no. 43, pp. 517-537.

2. Salama A., Anderson K., Toms J.S. Does community and environmental responsibility affect firm risk? Evidence from UK panel data 1994-2006. Business Ethics: A European Review, 2011, vol. 20 no. 2, pp. 192-204.

3. Hasseldine J., Salama A., Toms S. Quantity versus Quality: The Impact of Environmental Disclosures on the Reputations of UK Plcs. The British Accounting Review, 2005, vol. no. 37, pp. 231-248.

4. Lys T., Naughton J.P., Wang C. Signaling through corporate accountability reporting. Journal of Accounting and Economics, 2015, vol. 60, pp. 56-72.

5. Батаева Б.С. Корпоративное управление, корпоративная прозрачность и корпоративная ответственность. Управленческие науки в современной России, 2014, Т. 1, №1, cc. 35-39. [Batayeva B.S. Korporativnoye upravleniye, korporativnaya prozrachnost' i korporativnaya otvetstvennost' [Corporate governance, corporate transparency and corporate responsibility]. Upravlencheskiye nauki $v$ sovremennoy Rossii $=$ Management Science in Modern Russia, 2014, vol. 1, no. 1, pp. 35-39.].

6. Беляева И.Ю., Пухова М.М. Совершенствование системы корпоративной социальной ответственности путем интеграции в систему корпоративного управления. Вестник Самарского государственного экономического университета, 2016, №1,cc.79-83. [BelyayevaI. Yu., Pukhova M.M. Sovershenstvovaniye sistemy korporativnoy sotsial'noy otvetstvennosti putem integratsii v sistemu korporativnogo upravleniya [Improving the corporate social responsibility system through integration into the corporate governance system]. Vestnik Samarskogo gosudarstvennogo ekonomicheskogo universiteta $=$ Bulletin of Samara State University of Economics, 2016, no. 1, pp. 79-83.]. 
7. Измайлова М.А. Деловая репутация как фактор повышения конкурентоспособности компаний. Социально-экономическое управление: теория и практика, 2018, T. 3, №34, cc. 42-45. [Izmaylova M.A. Delovaya reputatsiya kak factor povysheniya konkurentosposobnosti kompaniy [Business reputation as a factor in increasing the competitiveness of companies]. Sotsial'no-ekonomicheskoye upravleniye: teoriya $i$ praktika = Socio-Economic Management: Theory and Practice, 2018, vol. 3, no.34, pp. 42-45.].

8. ельчевская Н.Р., Черненко И.М., Попова Е.В. Влияние корпоративной социальной ответственности на инвестиционную привлекательность российских компаний. Экономика региона, 2017, Т. 13, вып. 1, сс. 157-169. [Kel'chevskaya N.R., Chernenko I.M., Popova Ye.V. Vliyaniye korporativnoy sotsial'noy otvetstvennosti na investitsionnuyu privlekatel'nost' rossiyskikh kompaniy [The impact of corporate social responsibility on the investment attractiveness of Russian companies]. Ekonomika regiona $=$ Region Economy, 2017, vol. 13, no. 1, pp. 157-169.].

9. Развитие корпоративных стратегий и технологий в российских компаниях: монография / коллектив авторов; под науч. Ред. И.Ю. Беляевой, О.В. Даниловой, М.: Финансовый университет при Правительстве Российской Федерации (Москва), 2019. 387 с. [Razvitiye korporativnykh strategiy i tekhnologiy v rossiyskikh kompaniyakh: monografiya [Development of corporate strategies and technologies in Russian companies: monograph] kollektiv avtorov; pod nauch. Red. I.Yu. Belyayevoy, O.V. Danilovoy, M.: Finansovyy universitet pri Pravitel'stve Rossiyskoy Federatsii (Moskva), 2019. 387 p.].

\section{Сведения об авторе / About author}

Бадыкова Иделя Рашитовна, кандидат экономических наук, доцент кафедры бизнес-статистики и экономики, Казанский национальный исследовательский технологический университет. 420015 Россия, г. Казань, ул. Карла Маркса, 68. ORCID ID 0000-0002-9072-3856. E-mail: idelya.nizamova@gmail.com

Idelia R. Badykova, Candidate of Economic Sciences, Associate Professor of Business Statistics and Economics Department, Kazan National Research Technological University. 68 Karla Marksa St., Kazan, Russia 420015. ORCID ID 0000-0002-9072-3856.

E-mail: idelya.nizamova@gmail.com 